\title{
Developmentally programmed assembly of higher order telomerase complexes with distinct biochemical and structural properties
}

\author{
Eric C. Greene and Dorothy E. Shippen ${ }^{1}$ \\ Department of Biochemistry and Biophysics, Texas A\&M University, College Station, Texas 77843-2128 USA
}

In Euplotes crassus, telomerase is responsible for telomere maintenance during vegetative growth and de novo telomere synthesis during macronuclear development. Here we show that telomerase in the vegetative stage of the life cycle exists as a 280-kD complex that can add telomeric repeats only onto telomeric DNA primers. Following the initiation of macronuclear development, telomerase assembles into larger complexes of 550 kD, $1600 \mathrm{kD}$, and $5 \mathrm{MD}$. In the 1600-kDa and 5-MDa complexes, telomerase is more processive than in the two smaller complexes and can add telomeres de novo onto nontelomeric 3 ' ends. Assembly of higher order telomerase complexes is accompanied by an extended region of RNase V1 and RNase T1 protection in the telomerase RNA subunit that is not observed with telomerase from vegetatively growing cells. The protected residues encompass a highly conserved region previously proposed to serve as a platform for formation of higher order structures. These findings provide the first direct demonstration of developmentally regulated higher order telomerase complexes with unique biochemical and structural properties.

[Key Words: Telomerase; chromosome healing; Euplotes crassus; RNA footprinting; holoenzyme]

Received May 7, 1998; revised version accepted July 21, 1998.

The integrity of the telomere complex is essential for genome stabil ity in eukaryotes. The primary mechanism for generating and sustaining chromosome ends is through the action of telomerase, a ribonucleoprotein (RNP) that catalyzes the addition of telomeric DN A repeats (Grei der 1995; M el ek and Shi ppen 1996). Given the strong correlation between telomerase expression and cellular proliferation capacity in higher eukaryotes and tumorigenesis in humans (Greider 1998; Shippen and M CKnight 1998), understanding the functions and interactions of telomerase RN P constituents is of considerable importance.

Telomerase directs telomere repeat addition via reverse transcription of a short templating domain in its RNA subunit (Greider 1995). The most well-studied tel omerase RN As, found in ciliated protozoa, have a conserved secondary structure (Romero and Blackburn 1991; Bhattacharyya and Blackburn 1994; Lingner et al. 1994; Zaug and Cech 1995). Telomerase RN As identified in yeast and mammals are significantly larger than their ciliate counterparts (Singer and Gottschl ing 1994; Bl asco et al. 1995; Feng et al. 1995), and currently, no phylogenetic or structural data are avail able for these molecules.

The protein subunits of the telomerase complex are

${ }^{1}$ Corresponding author.

E-MAIL dshippen.tamu.edu; FAX (409) 845-9274. still being cataloged. The catalytic reverse transcriptase subunit (TERT), which was first purified from the hypotrichous ciliate Euplotes aediculatus (Lingner et al. 1997), has subsequently been identified in Tetrahymena, Saccharomyces cerevisiae, Schizosaccharomyces pombe, and mammals (Harrington et al. 1997a; Lingner et al. 1997; N akamura et al. 1997; M eyerson, et al. 1997; Collins and Gandhi, 1998). TERT proteins have several characteristic reverse transcriptase (RT) domains as well as a telomerase-specific motif. Point mutations within conserved residues of the RT domains inactivate tel omerase in vitro and reduce telomere length in vivo (Harrington et al. 1997a; Lingner et al. 1997).

Although coexpression of the telomerase RNA and TERT subunits is sufficient to reconstitute telomerase activity (Beattie et al. 1998; Collins and Gandhi 1998; Weinrich et al. 1998), two additional proteins, p80 and p95, have been reported to associate with the telomerase RN P (Collins et al. 1995; Harrington et al. 1997b; Nakayama et al. 1997). The Tetrahymena p80 and p95 bind to single-stranded telomeric DNA and the telomerase RNA in vitro, respectively (Gandhi and Collins 1998). Mammalian homologs of p80 copurify and/or coimmunoprecipitate with telomerase acti vity suggesting a tight association between p80, TERT, and the telomerase RNA (Harrington et al. 1997b; N akayama et al. 1997).

In addition to maintaining pre-existing tracts of telo- 
meres, telomerase can al so add tel omeric repeats di rectly onto nontel omeric DN A. Because this reaction stabilizes broken chromosomes, it is sometimes referred to as chromosome healing (Harrington and Greider 1991; Melek and Shippen 1996). De novo telomere formation can occur spontaneously following accidental or artificially induced chromosome breakage, or it may be part of a developmental program of coupled chromosome fragmentation and new telomere formation. Developmentally controlled de novo telomere formation is a process integral to the sexual cycle of ciliated protozoa (Prescott 1994).

The hypotrichous ciliate Euplotes crassus provides a useful system for studying both developmentally programmed telomere formation and telomere maintenance. As with other ciliates, E. crassus contains two nuclei, a transcriptionally active macronucleus and a transcriptionally silent germ-line micronucleus. During the sexual phase, the macronucleus is destroyed and a new macronucleus is generated from a copy of the micronucleus. This process involves extensive site-specific fragmentation of the micronuclear genome and de novo addition of telomeres by telomerase onto thousands of linear DNA molecules. In vitro experiments with $E$. crassus and Tetrahymena enzymes reveal that telomerase forms tel omeres on nontelomeric DN A by bypassing the requirement for Watson-Crick base pairing between DNA and the telomerase RN A to initiate synthesis at a specific residue in the RNA template (Melek et al. 1996; Wang and Blackburn, 1997; Wang et al. 1998). During subsequent vegetative growth, telomerase maintains telomeres on the ends of all the linear DN A molecules, replenishing terminal nucleotides lost as a consequence of semiconservative DN A replication (Prescott 1994).

The behavior of the $\mathrm{E}$. crassus telomerase in vitro mimics its distinct functions in vivo. Telomerase in isolated developing macronuclei efficiently extends both telomeric and nontelomeric DNA 3' termini, consistent with its role in de novo telomere formation. In contrast, telomerase from vegetative macronuclei, al though able to extend telomeric DN A substrates, is unabl e to extend nontel omeric 3' termi ni (M elek et al. 1996; Bednenko et al. 1997). Thus, the E. crassus telomerase undergoes a developmentally programmed switch in its specificity for DNA that precisely matches its substrates in vivo. The switch appears to be mediated in part by a soluble chromosome healing factor ( $\mathrm{CHF})$, which can be reconstituted with purified telomerase to facilitate telomere repeat addition onto nontelomeric 3' DNA ends (Bednenko et al. 1997). This observation implies that the Euplotes telomerase is a holoenzyme in the developing macronucleus, consisting of a core RN P particle that associates with additional subunits that modify enzyme activity.

Here, we show that telomerase in the vegetative macronucl eus exists as a $280-k D$ complex that is unable to extend nontelomeric DN A 3' termini. During development of a new macronucleus, three new larger telomerase particles appear, a 550-kD, 1600-kD, and a $\geqslant 5-M D$ complex. The larger complexes have structural and bio- chemical properties distinct from the 280-kD complex. M oreover, in contrast to the $280-k D$ complex, the $1600-$ $k D$, and the 5-MD particles processively elongate both telomeric and nontelomeric DN A 3' termi ni. These findings provide the first direct evidence for programmed assembly of telomerase into higher order complexes with distinct biochemical and structural properties.

\section{Results \\ Developmentally programmed assembly of higher order tel omerase compl exes}

To characterize telomerase interactions with $\mathrm{CHF}$ and other cellular components, we attempted to employ gentle purification techniques to copurify factor(s) that might directly bind the tel omerase RN A or catalytic subunit by use of gel filtration chromatography. S100 macronuclear lysates were prepared from E. crassus and telomerase activity was fractionated on a superose 6-gel filtration column. We made three changes rel ative to our previous purification protocol (Bednenko et al. 1997; Greene et al . 1998) that al lowed us to detect higher molecular weight complexes. First, we used significantly more material per purification; second, we added N P-40 to a final concentration of $0.1 \%$ during chromatography; and third, we added $0.1 \mathrm{mg} / \mathrm{ml}$ acetyl ated BSA to the fractions following collection. We suspect that the increased protein concentration of our samples stabilized the higher molecular weight complexes during chromatography (see below). Fractions were assayed with the telomeric DNA primer $\left(G_{4} T_{4}\right)_{3}$. Telomerase activity from vegetativel y growing Eupl otes eluted predominately as a single, symmetrical peak with an apparent molecular mass of 280-kD (Fig. 1). In addition, a less abundant higher molecular weight complex was observed in the void volume (Fig. 1, lanes 4-6).

Telomerase fractionated from developing macronuclear lysates showed a radical redistribution in the elution profile relative to telomerase isolated from vegetatively growing Euplotes. Telomerase from devel oping macronuclei eluted as a broad band of activity ranging from $\sim 500 \mathrm{kD}$ up into the column void volume (Fig. 2). Phosphorlmager quantitation of the first telomeric repeat (G3) reveal ed a peak of telomerase activity with an apparent molecular mass of 550-kD (Fig. 2, lane 17; data not shown). Two additional peaks were detected, one at $1600 \mathrm{kD}$ and one in the void, based on quantitation of products resulting from addition of the third telomeric repeat (G19) (Fig. 2, lanes 5,13; data not shown).

Because the exclusion size for Superose 6 is $\geqslant 5$ MD, this value was used to estimate the minimal molecular mass of telomerase complexes in the void volume. The high molecular weight complex from vegetatively growing cells has the same bi ochemical properties as the 280kD complex (see below). However, because the largest and the smallest telomerase complex from developing cells exhibit dramatically different biochemical properties, the larger complex is described in detail in this report. Hereafter, we will refer to this complex from developing cells as the 5-MD complex. 


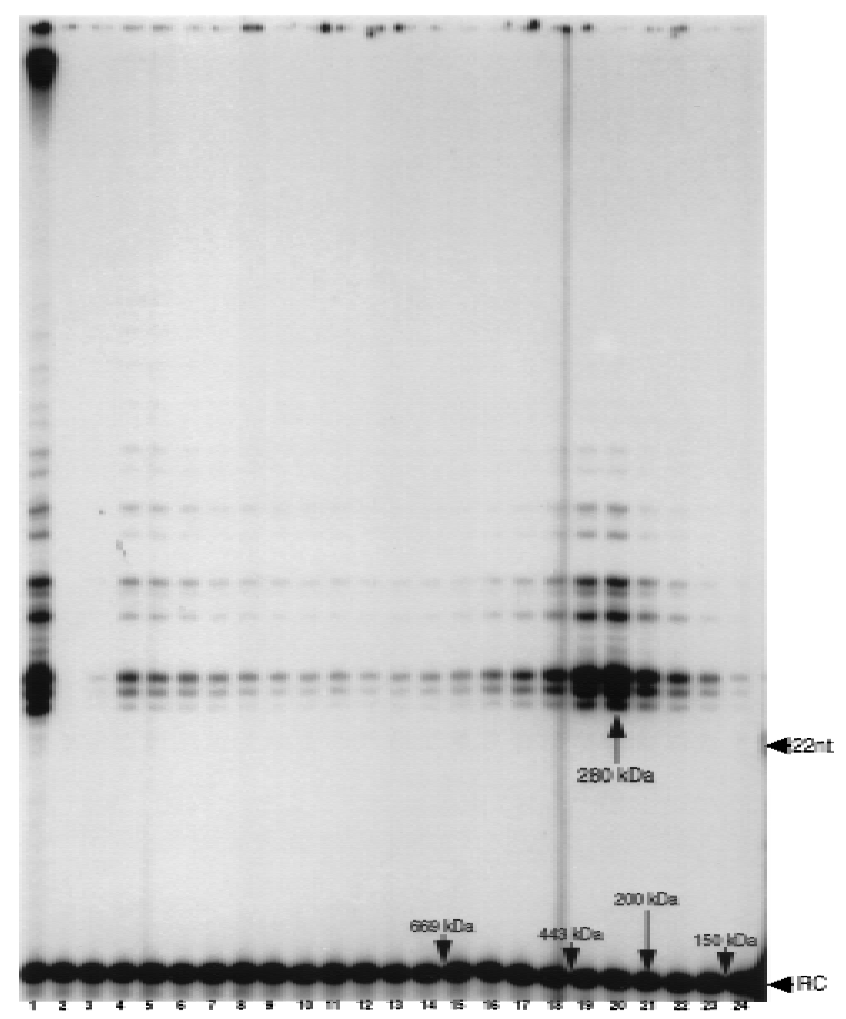

Figure 1. Telomerase from vegetative macronuclei elutes as a 280-kD complex and a high molecular weight complex in gel filtration. S100 macronuclear lysates from vegetatively growing E. crassus were fractionated by gel filtration chromatography on a superose 6 column. Fractions were assayed with $\left(G_{4} T_{4}\right)_{3}$. The positions of a $5^{\prime}{ }^{32} \mathrm{P}$-labeled 12 -mer recovery control $(\mathrm{RC})$ and a terminal transferase $3^{\prime 32} \mathrm{P}$-labeled 22 nucleotide marker are indicated. (Lane 1) S100; (lanes 2-24) even numbered fractions of the column elution profile. Elution positions of molecular weight standards are indicated. The high molecular mass products in lane 1 are the result of extension of contaminating DN A in the lysate and are not the result of processive extension of the primer (data not shown).

To ensure that the overlapping peaks of telomerase activity in devel oping macronuclei represented distinct complexes, the 550- and 1600-kD peaks were isolated, concentrated, and rechromatographed (Fig. 3A,B). Each complex el uted as a single symmetrical peak that corresponded to the same molecular mass observed with the S100 lysate. In addition, the 5-M D telomerase complex eluted in the void volume when rechromatographed (data not shown). We estimate a $25 \%$ recovery from the second round of chromatography for all the complexes on the basis of the amount of material requi red to obtain an equival ent signal in the primer el ongation assay.

The number of telomeric repeats detected with both the 550- and 1600-kD complexes increased foll owing enzyme concentration with polyethylene glycol (cf. Figs. 2, Iane 13, with 3B, Iane 2, and 2, Iane 17, with 3A, lane 2). However, the 1600-kD complex still generated significantly more repeats than the 550-kD complex (Fig. 3A,B, lanes 2). Foll owing the second round of chromatography, the processivity of the individual complexes remained unchanged (see Figs. 2, lane 13, and 3B, lane 13 and 2, lanes 17-18, and 3A, lanes 17-18). These results indicate that the higher order tel omerase complexes retain both molecular mass and catalytic properties following the second round of chromatography.

All three peaks of activity contained telomerase RN A, were inhibited by $R N$ ase $A$, and the $R N$ ase $A$ inhibition could be reversed by inclusion of the ribonuclease inhibitor RNAsin (data not shown). Additionally, all three peaks of tel omerase activity were resistant to treatment with DN ase I prior to fractionation and were stable during gel filtration chromatography in the presence of $0.1 \%$ N P40 (see Materials and Methods) or $1 \mathrm{~mm}$ potassium glutamate (data not shown). Taken together, these data argue that the large telomerase complexes are not constrained by DNA, nor are they nonspecific complexes held together by either electrostatic or hydrophobic interactions.

Previously, we noted a decrease in telomerase processivity foll owing partial purification (Greene et al. 1998). To determine if the decline in processivity could be attributed to the loss of a tel omerase-associated factor, the size of telomerase particles purified by ion-exchange chromatography as described previously (Greene et al.

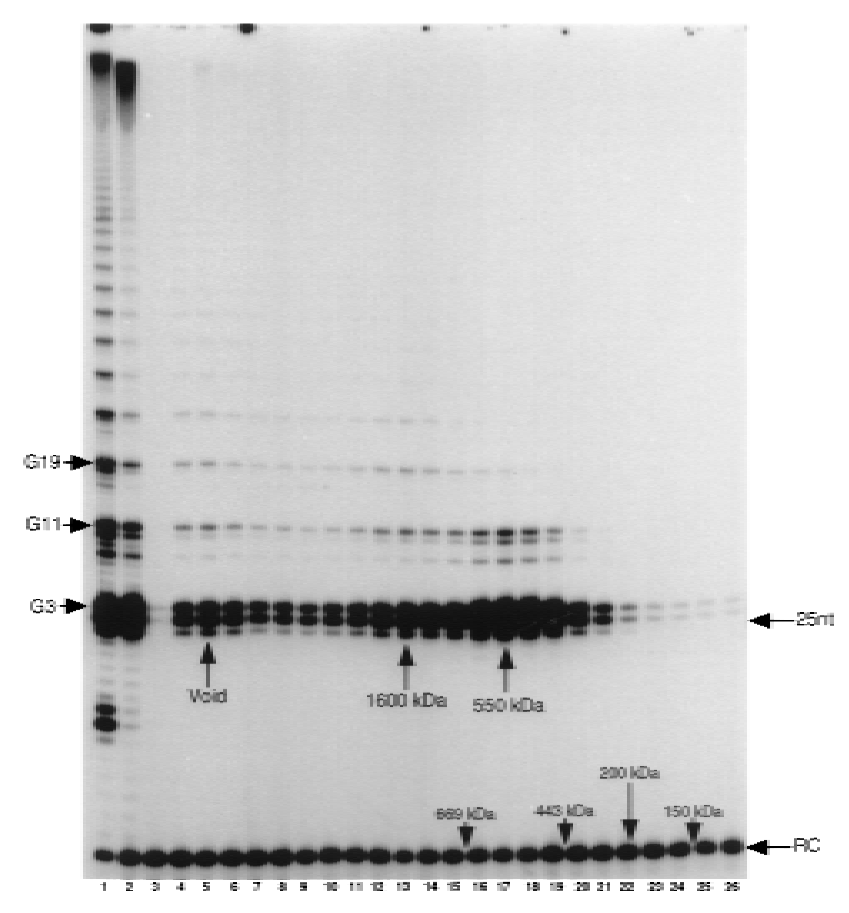

Figure 2. Telomerase from devel oping macronuclei assembles into higher order complexes. S100 macronucl ear lysates from E. crassus undergoing macronuclear development were fractionated by gel filtration chromatography as described in Fig. 1. Assays and molecular weight markers are as in Fig. 1. (Lane (1) Macronuclei; (lane 2) S100; (lanes 3-26) even-numbered fractions from the column elution profile. G3, 11, and 19 correspond to synthesis of the third, eleventh, and nineteenth dG, respectively, in the $G_{4} T_{4}$ repeated ladder. The peaks corresponding to distinctive telomerase complexes are indicated. 

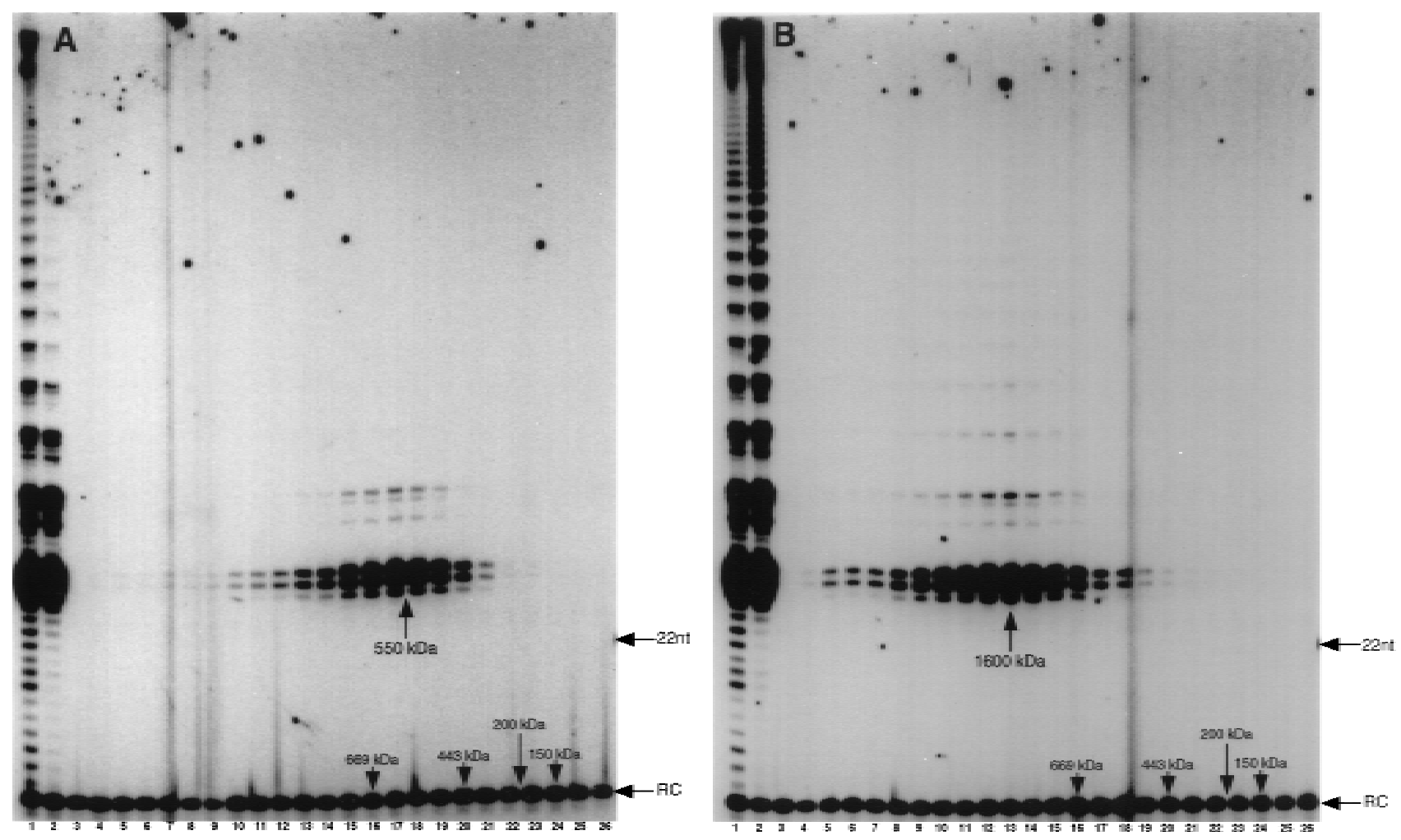

Figure 3. Distinct forms of telomerase are present in developing macronuclei. Individual telomerase complexes fractionated from developing macronuclear lysates were concentrated by dialysis into $40 \%$ PEG, rechromatographed by gel filtration and assayed for tel omerase activity. Rechromatographed 550-kD (Fig. 2, fractions 16-18) (A) and 1600-kD (Fig. 2, fractions 12-14) (B) complexes are shown. (Lanes 1) Reactions with a macronuclear lysate; (lane 2) reactions with the isolated, concentrated telomerase peaks (see $M$ aterials and $M$ ethods) prior to rechromatography; (lanes 3-26) superose 6 column el ution profile. Assays and molecular mass markers are as in Fig. 1.

1998) was determined. The partial ly purified telomerase from devel oping cells el uted as a single peak of $550 \mathrm{kD}$, which appeared to be identical to the 550-kD complex obtained directly from S100 lysates following gel filtration in terms of size and biochemical properties (data not shown and see below).

Primer specificities of the individual telomerase complexes

The developmental differences in primer specificity exhibited by the $E$. crassus tel omerase reflect the changing DN A substrates available to telomerase in vivo (Melek et al. 1996; Bednenko et al. 1997). To test whether the different telomerase complexes display biochemical properties consistent with the appropriate stage of the ciliate life cycle, complexes were reacted with primers that mimic the in vivo substrates of telomerase. The telomere maintenance function was examined by reacting complexes with a fully telomeric primer, $\left(\mathrm{G}_{4} \mathrm{~T}_{4}\right)_{3}$. The capacity for new telomere formation was measured with GT-13, a primer that contains the telomeric sequence GGGGTTTT at its 5 ' terminus and a stretch of 13 nontel omeric nucl eotides at its $3^{\prime}$ terminus. This chimeric primer is efficiently extended by telomerase in developing macronuclei, even though its $3^{\prime}$ terminus cannot form Watson-Crick base pairs with the RNA template. In contrast, telomerase in isolated vegetative macronuclei will not extend GT-13 with telomeric re peats (M elek et al. 1996; Bednenko et al. 1997),

The 280-kD telomerase complex from vegetative macronucl ei catal yzed the addition of tel omeric repeats onto the telomeric primer (Fig. 4, lane 1). The products of this reaction displayed an elongation profile characteristic of telomerase from vegetative $E$. crassus, wherein the strongest bands in the profile corresponded to an enzyme pause or dissociation after incorporation of the third $\mathrm{G}$ and fourth T in each GGGGTTTT repeat (Fig. 4, lane 1; Bednenko et al. 1997). A $\bar{s}$ with intact vegetative macronuclei, the $280-k D$ complex was unable to extend the GT-13 primer beyond the addition of a single $G$ residue (Fig. 4, lane 2; Bednenko et al. 1997). An additional product (marked with an asterisk) was obtained in these reactions, but it was not primer dependent, nor was it detected on further purification of the 280-kD telomerase complex (data not shown). The high molecular weight complex from vegetative cells displayed the same properties as the 280-kD complex in terms of primer specificity, processivity and profile of elongation products (data not shown). We note that the inability of the 280- 


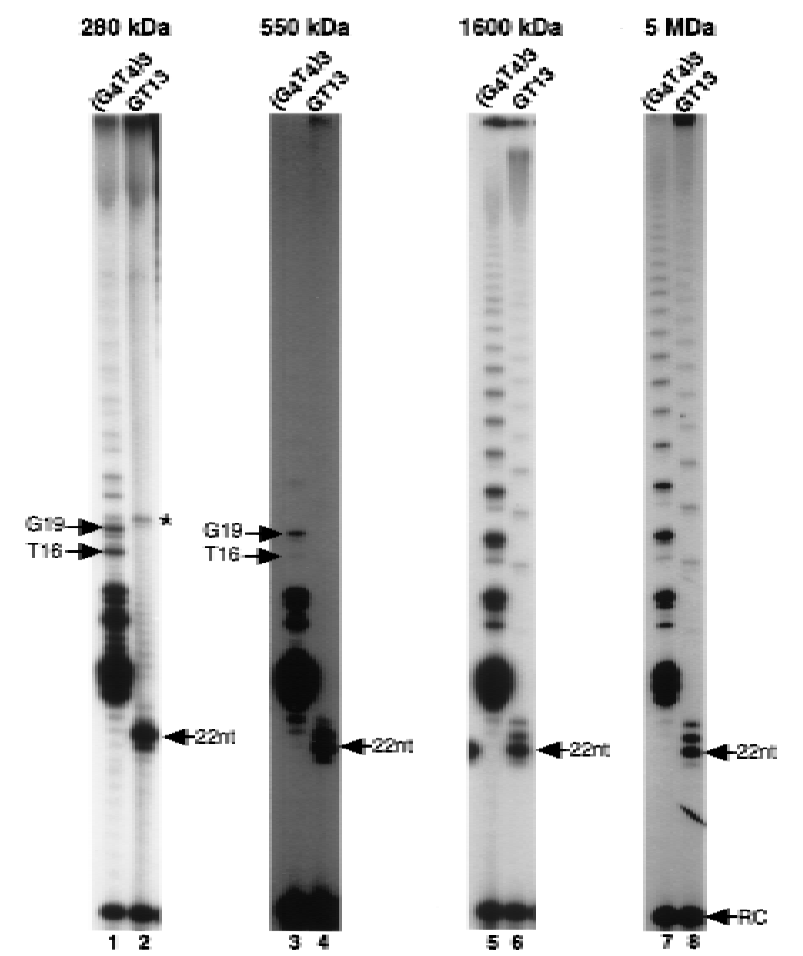

Figure 4. Individual telomerase complexes show unique biochemical properties with respect to primer utilization and processivity. Telomerase complexes fractionated by gel filtration were assayed with $\left(\mathrm{G}_{4} \mathrm{~T}_{4}\right)_{3}$ or the chimeric primer GT-13 (GGGGTTTTACTACGCGATCAT). (Lanes 1,2) Reactions with 280-kD vegetative complex; (lanes 3,4) 550-kD developmental complex; (lanes 5,6) 1600-kD developmental complex; (lanes 7,8) the developmental 5-MD complex. The migration position of the fourth $T$ and/or third $G$ residue in the TTTTGGGG elongation profile are indicated (T16 and G19). $\left.{ }^{*}\right)$ The band in the $280-k D$ preparation is not primer dependent and does not copurify further with telomerase activity. An overexposure of 550-kD complex assays is shown to emphasize the lack of processive products.

$\mathrm{kD}$ and high molecular weight compl exes to extend nontelomeric DNA directly reflects the properties of telomerase in the intact vegetative macronucleus.

Like the 280-kD complex, the 550-kD complex isolated from developing macronuclei was not able to extend GT-13 beyond one to two dG residues (Fig. 4, lane 4). In addition, the 550-kD complex was less processive in extending a telomeric primer than the S100 lysate and only catalyzed the addition of approximately one to three tel omeric repeats (cf. Figs. 2, Iane 2, and 4, lane 3). The 550-kD complex, like the other devel opment-specific complexes, generated elongation products in which pauses occurred predominantly after the addition of the third G in the TTTTGGGG repeat (Fig. 4, cf. Ianes 1 and 3). This elongation profile is characteristic for telomerase from devel oping macronuclei (Bednenko et al. 1997).

The two larger telomerase complexes of $1600 \mathrm{kD}$ and $5 \mathrm{MD}$ displayed strikingly different biochemical properties from the smaller telomerase complexes. Both of the larger complexes added multiple tel omeric repeats onto the telomeric primer $\left(\mathrm{G}_{4} \mathrm{~T}_{4}\right)_{3}$ (Fig. 4, lane 5,7), exhibiting significantly greater processivity than was observed for either the 280- or the 550-kD particles (Fig. 4, lanes 1,3). All of our telomerase reactions were carried out under the same conditions. N evertheless, such dramatic differences in enzyme processivity for the $\mathrm{E}$. crassus telomerase have not been observed with subtle changes in primer or salt concentration ( $E$. Greene, J. Bednenko, and D. Shippen, unpubl.). Furthermore, in contrast to findings reported for the E. aediculatus telomerase (Hammond and Cech 1997), we failed to detect any change in E. crassus telomerase processivity when dGTP concentrations were varied over a 400-fold range (J. Bednenko and D. Shippen, unpubl.). The only significant differences in enzyme processivity that we have observed occurred during purification of $\mathrm{E}$. crassus telomerase (Greene et al. 1998).

The most remarkable distinction between the two smaller complexes and the 1600-KD and 5-MD complexes was in primer specificity. The 1600-kD and 5-MD complexes efficiently and processively el ongated GT-13 (Fig. 4, lane 6,8). The ability of these complexes to directly el ongate nontel omeric $3^{\prime}$ ends indicates that $\mathrm{CHF}$ is associated with higher order telomerase assemblies isolated from developing macronuclei.

Each telomerase complex was tested for the ability to utilize fully nontel omeric substrates. In the absence of a G-rich telomeric cassette at the primer 5 ' terminus, none of the complexes efficiently extended a nontelomeric $3^{\prime}$ end (data not shown). In addition to its RT activity, the E. crassus telomerase is associated with an endonucl ease activity that preferentially cleaves at the junctions of telomeric and nontel omeric DN A (M elek et al. 1996; Greene et al. 1998). This activity has been postulated to serve a proofreading function for telomerase and/or to participate in chromosome fragmentation. All of the telomerase complexes catalyzed endonucleolytic cleavage of DN A ol igonucleotides (data not shown), supporting the conclusion that the nuclease activity is intrinsic to the core telomerase RN P (Melek et al. 1996; Bednenko et al. 1997; Greene et al. 1998).

Structurally distinct tel omerase RNP complexes in developing and vegetative macronuclei

The ciliate telomerase RNAs share a phylogenetically conserved secondary structure and contain several conserved sequences predicted to be important for telomerase function (Romero and Blackburn 1991; Lingner et al. 1994). In addition, the Tetrahymena thermophila tel omerase RNA has been examined in vivo and in vitro and footprinting studies support the phylogenetically predicted structure (Bhattacharyya and Blackburn 1994; Zaug and Cech 1995). Because our results indicated that the Euplotes telomerase exhibits different biochemical properties as a function of development, we reasoned that additional levels of modification might be detected in telomerase RN P architecture. Therefore, we examined the accessi bility of the telomerase RN A to chemical 
modification and ribonuclease cleavage in the context of the RNP particle.

First, chemical probing was undertaken to identify single-stranded, accessible regions of the RNA in intact macronuclei. Intact macronuclei were treated with dimethylsulfoxide (DMS), RNA was isolated, and modifications were detected by primer extension (Zaug and Cech 1995). The resulting pattern of modification was in good agreement with the proposed secondary structure for the Euplotes telomerase RN A (Lingner et al. 1994). $\mathrm{N}$ o significant differences between telomerase from developing and vegetative macronuclei were observed (data not shown).

Additional structure probing was performed with endoribonucleases. In this case, macronuclei were incubated with limiting amounts of either RN ase V1 (cleaves either double-stranded RNA or single-stranded, structured RNA) or RN ase T1 (cleaves single-stranded guanines). Only limited regions of the RN A were accessible to nuclease digestion; the vast majority of RNA was completely protected. RN ase V1 treatment revealed an accessible regi on near the $5^{\prime}$ end of the RN A (nucleotides
11 and 12), which was cleaved in both vegetative and devel oping macronuclei (Fig. 5A,C). These cl eavage sites localized to a region predicted to be single stranded on the basis of the phylogenetic model. However, using computer modeling for lowest free-energy structures (Zucker 1989), we noted the potential for a thermodynamically stable helix in this region (Fig. 5C).

Reactions with RN ase V1 uncovered a dramatic difference in telomerase RN P particles present in intact developing and vegetati ve macronuclei. N ucl eotides 109 in helix I and 119 in the adjacent portion of helix IV were accessible to cleavage by RNase V1 in intact macronuclei from vegetative cells, but were not accessible in intact developing macronuclei (Fig. 5A,C). These nucleotides encompass a conserved region (Fig. 5C, larger, bold type) predicted previously to serve as a site for the binding of tel omerase-associated factors (Lingner et al. 1994).

Another devel opmentally regulated structural distinction was observed in reactions with RN ase T1. Prominent cleavage sites were detected at nucleotides 51 and 149 in both intact developing and vegetative macronuclei (Fig. 5B,C). However, a cleavage site at nucleotide
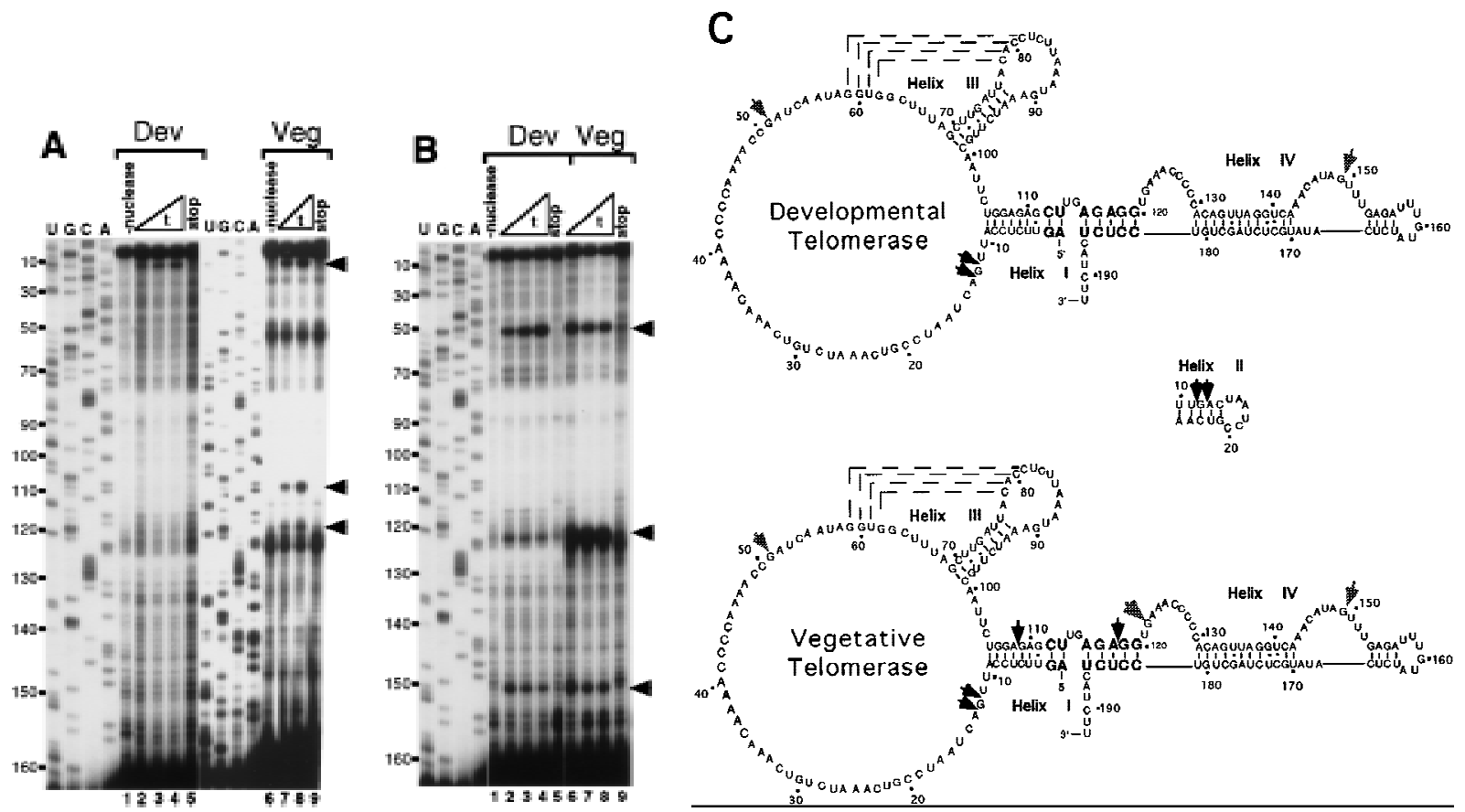

Figure 5. Accessibility of the telomerase RNA in intact macronuclei is developmentally regulated. (A) Footprinting reactions with RN ase V1. (Lanes 1,6) Extension reactions without prior ribonucl ease treatment; (lanes 5,9) (label ed stop) reaction termination controls (see M aterials and M ethods); (lanes 2-4) 5-, 10-, and 15-min RN ase V1 footprint reactions, respectively, with devel oping macronuclei; (lanes 7,8) 5- and 10-min RN ase V1 footprint reactions with vegetative macronucl ei. Cleavage sites are indicated with arrowheads and sequencing ladders used to map the sites of ribonuclease accessibility are denoted. (B) Footprinting reactions with RN ase T 1. Control lanes and sequencing markers are label ed as in A. (Lanes 2-4,6-8) 5-, 10-, and 15-min reactions with RN ase T1; (lane 9) stop reaction. Predominant cleavage sites are indicated with arrowheads. The RN ase T1 cl eavage site at position 122 in the vegetative macronuclei is near a nonspecific band at nucleotide 125. The background level of damage at this site varied from experiment to experiment and Phosphorlmager analysis confirmed the increased intensity of this band in the presence of RN ase T1 (data not shown), ruling out the possi bility that it is solely the result of nonspecific RN A damage. (C) Ribonucl ease cl eavage sites superimposed on the phylogentical ly predicted structure of the E. crassus tel omerase RN A (Shippen-Lentz and Blackburn 1990; Lingner et al. 1994). Conserved nucleotides 112-120 are shown in larger, boldface type and a potential thermodynamically stable helix corresponding to nucleotides $10-25$ is depicted. N ucleotides 36-50 comprise the templating domain. RN ase V1 cleavage sites, black arrowheads, and RN ase T1 sensitive sites, gray arrowheads, are indicated. 
122 (Fig. 5B, cf. lanes 6-8 and lane 9), immediately adjacent to the RNase V1 accessible region, was observed only in vegetative macronuclei (Fig. 5B,C). We conclude from these data that an extended regi on of nuclease protection encompasses a conserved region in the telomerase RN A during macronucl ear development.

The appearance of the protected regi on of helices I and IV of the telomerase RNA in intact macronuclei was temporally coupled to the disappearance of the $280-\mathrm{kD}$ telomerase complex during macronuclear development (Fig. 1,2,5; data not shown). To determine if the extended footprint was directly related to the increased apparent molecular mass of telomerase during development, RNase V1 footprints were performed on the individual telomerase complexes, isolated by gel filtration. RN ase V1 treatment revealed two structural distinctions in telomerase present in intact macronuclei relative to isolated telomerase complexes (Fig. 6). First, all of the isolated telomerase complexes showed decreased sensitivity to RN ase V1 at nucleotides 11 and 12 compared with telomerase present in intact macronuclei (cf. Figs. 5A and $6 A-C$ ). Second, a new region of $R N$ ase $V 1$ sensitivity at nucleotide 53 was detected in the isolated 550- and $1600-k D$ complexes that was not observed with intact developing macronuclei (cf. Figs. 5A and 6B and C). This site shows significant background cleavage in both the vegetative macronuclei and the isolated $280-k D$ complex (Figs. 5A and 6A).

As with telomerase present in intact vegetative macronuclei, telomerase RNA in the isolated 280-kD complex exhibited sensitivity to RN ase V1 in helix I (nucleotide 109) (Figs. 5A and 6A). Slight background at nucleotide 119 obscured any cleavage that may have been the result of $\mathrm{RN}$ ase $\mathrm{V} 1$ treatment in the isolated $280-\mathrm{kD}$ complex (Fig. 6A, lanes 1,4,5). Significantly, nucleotide 109 was completely protected from RN ase V1 digestion in isolated 550-kD, 1600-kD, and 5-M Da complexes (Fig. $6 B, C$; data not shown) as it was in the intact developing macronucleus (Fig. 5A). Thus, the increased apparent molecular mass of telomerase RNP complexes present during macronuclear development is directly related to the nucl ease protection in helix I of the telomerase RN A subunit.

\section{Discussion}

E. crassus is one of the few model systems in which the two distinct modes of telomere synthesis, telomere maintenance, and de novo telomere formation can be readily observed. Furthermore, because the biochemical properties of tel omerase switch in response to the changing in vivo substrates for the enzyme (Melek et al. 1996; Bednenko et al. 1997), E. crassus provides a unique opportunity to investigate the mechanism of DNA recognition and processing by telomerase. In this study, we used protein purification in conjunction with RNA structure probing to identify development-specific telomerase complexes and putative binding sites for potential new telomerase-associated factors that may be intimately involved in the switch in telomerase's DNA specificity.

\section{Higher order tel omerase complexes}

During vegetative growth of $\mathrm{E}$. crassus, telomerase predominately exists as a single 280-kD complex capable of extending telomeric primers with additional telomeric DNA. Although we have not yet defined all of the components of this complex, it resembles the telomerase RN P purified to homogeneity from vegetatively growing E. aediculatus, in terms of its apparent molecular mass ( $280 \mathrm{kD}$ vs. $230 \mathrm{kD}$ ) and relatively low processivity with telomeric DNA primers (Lingner and Cech 1996; Hammond et al. 1997). The E. aediculatus complex harbors the telomerase RN A, a 123-kD TERT, and a 43-kD protein subunit (Lingner and Cech 1996; Lingner et al. 1997). In the early steps of purification, a small ( 45 kD) decrease in the size of the E. aediculatus RN P particle was noted that was attributed to the loss of a subunit or proteolytic removal of a nonessential fragment. How-
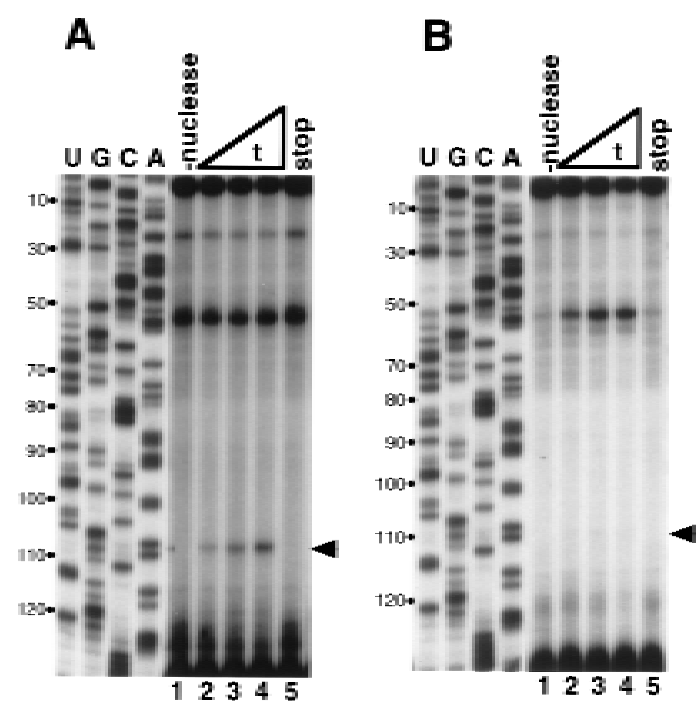

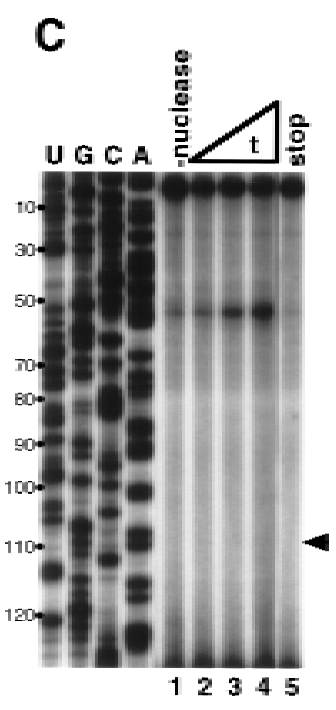

Figure 6. Ribonuclease protection in isolated tel omerase complexes. Isolated tel omerase complexes were footprinted separately as in Fig. 5. RN ase V1 footprints of the 280-(A), 550- (B), and 1600-kD (C) complexes are shown. Lane designations are as in Fig. 5. The position of nucleotide 109 is indicated with an arrowhead. For each panel, equivalent amounts of sequencing ladder were loaded and the exposures were adjusted until the signals of full-length RNA were approximately the same. 
ever, no specific differences in telomerase activity were reported to coincide with the reduction in apparent molecular mass (Lingner and Cech 1996). Given the small change in particle size and the fact that the enzyme was purified from vegetatively growing cells, it is unlikely that the putative subunit/fragment is related to the higher order telomerase complexes that we observed during E. crassus macronuclear development. Currently, it is impossible to obtain synchronized preparations of conjugating $\mathrm{E}$. aediculatus in the laboratory, and hence, a comparative analysis of telomerase complexes from developing cells of the two Euplotes species is not feasible. $\mathrm{N}$ evertheless, the available information for telomerase from vegetative cells argues strongly that the $280-k D$ complex represents a core telomerase particle, containing a minimum compliment of factors in addition to the telomerase RNA and the catalytic TERT subunit.

During macronuclear development, E. crassus telomerase assembles into a series of distinct higher order complexes with apparent molecular masses of $550 \mathrm{kD}$, 1600 kD, and 5 MD. Like the 280-kD complex from vegetative cells, the 550-kD complex fails to utilize nonteIomeric $3^{\prime}$ ends. In addition to their size differences, the 280-kD and 550-kD complexes can be distinguished mechanistically by the profiles of their products (see Fig. 4 , lanes 1,3$)$. This variation in telomerase product profiles was noted previously in assays with intact vegetative and devel oping macronucl ei (M elek et al. 1996; Bednenko et al. 1997). The larger mass of the 550-kD complex is consistent with binding of one or more additional subunits that alter the basic mechanism of telomere synthesis. Another possibility is that the telomerase RNA and/or the catal ytic subunit is modified during development in a way that results in subtle changes in how $\mathrm{T}_{4} \mathrm{G}_{4}$ repeats are generated.

The 1600-kD complex exhibits structural and biochemical properties clearly distinct from the smaller telomerase RN P particles. Specifically, this complex processively extends both telomeric and nontelomeric 3' termini. Therefore, we speculate that it represents a telomerase holoenzyme. Although telomerase complexes that el ute in the void of a superose 6-gel filtration column can be isolated from the macronuclei of both vegetative and developing cells, the available information does not indicate whether these complexes represent specific tel omerase assemblies or aggregates. In all of our assays, the biochemical properties of the higher order vegetative complex were identical to the $280-\mathrm{kD}$ complex. Similarly, the 5-MD complex from developing cells displayed the same properties as the 1600-kD complex.

The S. cerevisiae telomerase RNP has been shown recently to exist as a multimer (Prescott and Blackburn 1997). It is conceivable that the higher order telomerase complexes from Euplotes represent a developmentally regulated multimerization of the RNP. The apparent molecular masses of the compl exes $(280 \mathrm{kD}, 550 \mathrm{kD}$, and 1600 kD) are not inconsistent with a monomer-to-dimerto-tetramer assembly. To investigate this idea further, we examined the isol ated $550-k D$ complex under a vari- ety of chromatography conditions (Greene et al. 1998; E. Greene and D. Shippen, unpubl.). In no case did we detect breakdown of the 550-kD complex into a 280-kD particle or aggregation into a 1600-kD or 5-MD complex (data not shown), indicating that the Euplotes telomerase complexes are stable. Although we have no direct evidence for or against RN P multimerization, the developmental stage specificity of the higher order complexes argues that additional cofactors and/or modifications are required for assembly. Recently, we optimized conditions that allow purification of telomerase over seven sequential chromatography steps without significantly altering either the biochemical properties or the sizes of the individual telomerase complexes (E.C. Greene and D.E. Shippen, unpubl.). A nalysis of complex constituents is currently underway and should reveal whether the Eupl otes telomerase associates with a novel set of proteins during macronuclear development.

Two obvious candidates that could be members of a telomerase higher order complex are p80 and p95, the nucleic acid binding proteins associated with the Tetrahymena and mammalian telomerases (Collins et al. 1995; Harrington et al. 1997b; Nakayama et al. 1997; Gandhi and Collins 1998). Antibodies against the Tetrahymena p80 and p95 fail to cross-react with proteins in E. crassus extracts (E.C. Greene, D.E. Shippen, and K. Collins, unpubl.). In addition, the region of the Euplotes telomerase RNA protected from ribonuclease digestion in developing macronuclei is not conserved in the Tetrahymena tel omerase RN A (Lingner et al . 1994). Thus, if a p80 homolog is associated with the E. crassus telomerase, it does not assemble in the same way in Euplotes and Tetrahymena tel omerase RN P particles. One important indication of the dramatic divergence of these two RN Ps is that the Tetrahymena tel omerase, in contrast to the Eupl otes enzyme, has an intrinsic ability to add telomeric sequences onto completely nontelomeric DNA substrates in vitro. This activity is apparently not modified during development (Wang and Blackburn 1997).

Changes in telomerase RNP architecture during Euplotes development

The ciliate tel omerase RN As share a common secondary structure and several nucleotides that are absolutely conserved (Romero and Blackburn 1991; Lingner et al. 1994). In the hypotrichous ciliate telomerase RNAs, one conserved sequence is located between nucleoti des 112120 , encompassing some of the residues in helices I and IV (Fig. 5C). As a consequence of its strict sequence conservation, this domain was postulated to serve as a platform for the formation of a tel omerase higher order complex (Lingner et al. 1994; Nugent and Lundblad 1998). Our results support this hypothesis in that ribonuclease accessibility to this region displays a dynamic and developmentally controlled protection profile.

Protection of this region in the telomerase RN A coincides with changes in both apparent molecular mass and the biochemical properties of purified RN P particles. In every case that we examined, ribonuclease accessibility 
of helices I and IV in intact macronuclei accurately predicted the presence or absence of the 280-kD telomerase complex, suggesting that these two properties may be functionally related. Furthermore, because the higher order telomerase complexes (1600 kD and 5 MD) exhibit a ribonuclease protection profile similar to that found in intact devel oping macronuclei, the increase in apparent molecular mass is likely to be mediated in part by direct binding of one or more factors to helix I of the tel omerase RNA. Although our results do not rule out a drastic alteration of the RN A secondary and/or tertiary structure rather than direct protection from a bound factor, such an alteration would be surprising in the absence of a causative factor. In either case, the data argue strongly for the existence of developmentally regulated factor(s) that directly interact with telomerase.

\section{Possible in vivo roles for telomerase higher} order complexes

In the developing macronucleus of ciliates, there are at least two opportunities for telomerase to interact with other cellular machineries. First, studies in Tetrahymena and Eupl otes reveal that chromosome fragmentation and de novo telomere formation are tightly coupled. Intermediates lacking telomeres have never been detected, implying an intimate association between the fragmentation machinery and telomerase (Roth and Prescott 1985; Yao et al. 1990; Fan and Yao 1996). Second, aphidicolin treatment of developing Eupl otes macronuclei alters telomere synthesis by telomerase, indicating telomeric G-strand synthesis is cl osely associated with synthesis of the C-rich telomeric strand by Pol- $\alpha$ / primase (Fan and Price 1997).

Given the distinct biochemical properties of Euplotes telomerase complexes, we can make predictions concerning their in vivo roles. The $280-k D$ core telomerase complex displays properties expected for an enzyme involved in telomere maintenance. This role requires interaction with pre-existing tel omeric DNA, but not with nontel omeric 3' ends. The 550-kD complex, the smallest telomerase particle detected during macronuclear development, nonprocessively extends telomeric substrates, but cannot utilize non-telomeric substrates. This complex could fulfill a function in telomere maturation following initial telomere addition, or it could have a role in tel omere maintenance during the final rounds of DN A replication before macronuclear development is completed (Prescott 1994). Alternatively, the 550-kD complex may represent an intermediate on the pathway to assembly of the larger complexes. One piece of evidence supporting this later model is that all of the telomerase complexes from developing macronuclei generate the same pausing profile of elongation products, indicating that the same mechanism of repeat synthesis is employed.

The 1600-kD and the 5-M D tel omerase complexes perform processive synthesis on both telomeric and nonteIomeric primers 3' ends. Extension of nontelomeric DNA by the E. crassus telomerase in vitro mimics the de novo telomere formation reaction in vivo. In both cases, telomerase initiates synthesis by adding a specific permutation of the eight nucleotide telomeric repeat, GGGGTTTT (Klobutcher et al. 1981; Vermeesch and Price 1994; Melek et al. 1996). In our assays, a 5' G-rich sequence is required for extension of nontelomeric $3^{\prime}$ ends in vitro (Melek et al. 1996); none of the isolated telomerase complexes el ongate an enti rel y nontel omeric primer. Because a corresponding G-rich region is absent from chromosome break sites in vivo (Klobutcher et al. 1981), we and others have proposed that an unidentified protein cofactor or another unknown cis-acting DN A sequence element recruits telomerase to the break (Coyne et al. 1996; Melek et al. 1996; Bednenko et al. 1997). On the basis of their biochemical properties, the 1600-kD and the 5-MD telomerase complexes from developing macronuclei contain $\mathrm{CHF}$ and perhaps other components of the machinery involved in chromosome fragmentation and telomeric C-strand synthesis. The more processive nature of these complexes compared with the 550-kD particle is also consistent with an enzyme that generates the oversized telomeres initially added to DNA ends during macronuclear development in Euplotes (Roth and Prescott 1985; Vermeesch and Price 1994).

Finally, it should be noted that many telomerases exhibit apparent molecular masses si gni ficantly larger than predicted from the size of the telomerase RNA and a TERT (Lue and Peng 1997; Nakayama 1997; Wang and Blackburn 1997; Nakamura and Cech 1998). Thus, telomerase is likely to exist as a holoenzyme in other organisms.

\section{Materials and methods}

\section{Macronuclei preparation}

E. crassus stains LW13 and LW14 were grown in 40- to 80-liter aliquots at a density of $\sim 10^{3}$ cells $/ \mathrm{ml}$. Prior to harvesting, cells were starved 5-6 days and then mated as described previously (Greene et al. 1998). For preparation of vegetative macronuclei, E. crassus strain LW13 was grown overnight in 20-liter al iquots of dense algae and cells were harvested before the algae was completely consumed. Vegetative macronuclei were isolated as described previously (Bednenko et al. 1997). Macronuclei were resuspended in TM G buffer [20\% glycerol, $30 \mathrm{~mm}$ Tris- $\mathrm{HCl}(\mathrm{pH}$ 7.5), $0.1 \mathrm{~mm} \mathrm{M} \mathrm{gCl}_{2}, 1 \mathrm{~mm}$ DTT] containing protease and ribonuclease inhibitors $(0.1 \mathrm{~mm}$ PMSF, $12.5 \mu \mathrm{g} / \mathrm{ml}$ antipain, $1.7 \mu \mathrm{g} /$ $\mathrm{ml}$ aprotinin, $10 \mu \mathrm{g} / \mathrm{ml}$ chymostatin, $10 \mu \mathrm{g} / \mathrm{ml} \mathrm{E64,} 1 \mu \mathrm{g} / \mathrm{ml}$ leupeptin, $7 \mu \mathrm{g} / \mathrm{ml}$ pepstatin A and $10 \mathrm{~mm}$ vanadyl ribonucleoside complex), frozen with liquid nitrogen and stored at $-80^{\circ} \mathrm{C}$ until use. Prior to S100 Iysate preparation, macronuclei were adjusted to $1 \%$ N P-40 and $0.5 \mathrm{M}$ potassium glutamate (KGlu). Macronuclei were lysed by French Press at 16,000 psi and lysates centrifuged at $40,000 \mathrm{rpm}$ for $1 \mathrm{hr}$ in a TL100 rotor prechilled to $4^{\circ} \mathrm{C}$. The resulting lysates were divided into $250-\mu \mathrm{l}$ al iquots, frozen with liquid nitrogen, and stored at $-80^{\circ} \mathrm{C}$ until use. Protein concentrations were determined by Bradford assay.

Fractionation of telomerase complexes

Tel omerase complexes were fractionated by gel filtration at $4^{\circ} \mathrm{C}$ on a Superose 6 (separation range: $5 \times 10^{3}-5 \times 10^{6}$ Daltons) HR 
10/30 column (Pharmacia) with FPLC. Columns were pre equilibrated with TMG containing $150 \mathrm{~mm} \mathrm{NaCl}, 0.1 \mathrm{~mm}$ PM SF and $0.1 \%$ N P-40. S100 lysates (0.2 mg protein) were loaded in 200- $\mu \mathrm{l}$ al iquots and separated at a flow rate of $0.1 \mathrm{ml} / \mathrm{min}$. Fractions were adjusted to $0.1 \mathrm{mg} / \mathrm{ml}$ acetylated BSA (U.S. Biochemical) following collection. Column calibration was performed with blue dextran (void volume), thyroglobulin (669 kD), apoferritin (443 kD), $\beta$-amylase (200 kD), and ADH (150 $k D$ ) as size standards. The el ution volumes of the size standards were determined by monitoring absorbance at $280 \mathrm{~nm}$. For re chromatography, individual peaks were collected and concentrated four- to fivefold by dialysis into TMG containing $40 \%$ polyethylene glycol 8000 (PEG). The following fractions (see Fig. 2) were combined as peak activities: 550-kD complex (fractions 16-18), 1600-kD complex (fractions 12-14), and 5-MD complex (4-6). The individual complexes were rechromatographed under conditions identical to those for S100 lysates with the exception that acetylated BSA $(0.1 \mathrm{mg} / \mathrm{ml})$ was included in the running buffer as a stabilizer. The largest telomerase complex el uted outsi de the effective fractionation range of the column. Therefore, we estimated the minimal molecular mass of this complex as 5 MD.

\section{Telomerase assays}

Tel omerase reactions were performed in a total volume of $40 \mu \mathrm{l}$ and incubated at $30^{\circ} \mathrm{C}$ for $1 \mathrm{hr}$. The final concentrations of re action components were $50 \mathrm{~mm}$ Tris- $\mathrm{HCl}$ (pH 8.0), 10\% glycerol, $5 \mathrm{~mm} \mathrm{M} \mathrm{gC}_{2}, 20 \mathrm{~mm}$ EGTA, $75 \mathrm{~mm} \mathrm{~N} \mathrm{aCl}, 0.05 \% \mathrm{~N} \mathrm{P}-40,0.1$ $\mathrm{mm}$ dTTP, $0.25 \mu \mathrm{M}\left[\alpha^{32} \mathrm{P}\right] \mathrm{dGTP}(800 \mathrm{Ci} / \mathrm{mmole}), 0.1 \mathrm{mg} / \mathrm{ml}$ acetylated BSA (U.S. Biochemical), $1 \mathrm{~mm}$ DTT, $1 \mathrm{~mm}$ spermidine and $0.4 \mu \mathrm{m}$ primer. Reactions were stopped by the addition of EDTA to $10 \mathrm{~mm}$ and products isolated by phenol/chloroform extraction followed by ethanol precipitation. A $5^{\prime 32} \mathrm{P}$-labeled 12-mer was added to the EtOH precipitation as a recovery control. Products were resolved on $10 \%$ sequencing gels and detected by autoradi ography. The DN A primer was in large excess relative to telomerase to ensure that products containing more than a single telomeric repeat result from multiple rounds of processive synthesis (M orin 1989; Lee and Blackburn 1993; Melek et al. 1996).

\section{Footprinting reactions}

Macronuclei were adjusted to $\sim 10^{4}$ nuclei $/ \mathrm{ml}$ in TMG. RN ase V1 (Pharmacia) or RN ase T1 (GIBCO BRL) were added to 3 units or 10 units, respectively, per $100 \mu \mathrm{l}$ of macronuclei. Footprint reactions with isolated telomerase complexes were performed with 0.01 units of RNase V1 per $150-\mu$ l sample ( 10-fold less telomerase than present in the footprints with intact macronuclei, data not shown). Reactions were incubated at room temperature and $100-\mu \mathrm{l}$ al iquots removed at the indicated intervals. Footprinting reactions were adjusted to $0.3 \mathrm{M} \mathrm{NaOAc}(\mathrm{pH} 5.2)$ in a total volume $200 \mu \mathrm{l}$ and RNA isolated by sequential phenol (pH 4.3)/chloroform and chloroform extractions. Reaction termination controls (stop) were performed in which ribonuclease was added to samples and reactions terminated with no incubation to ensure that no RNA damage was incurred during deproteinization and RNA isolation. No RNA damage was detected during the course of the incubations in the absence of exogenously added ribonuclease (data not shown). RNA was precipitated from the aqueous phase by addition of $360 \mu \mathrm{l}$ of isopropanol, $40 \mu \mathrm{l} 3 \mathrm{M} \mathrm{N} \mathrm{aOAC}(\mathrm{pH} 5.2)$, and $2 \mu \mathrm{l}$ of glycogen $(\sim 7$ $\mu \mathrm{g} / \mu \mathrm{l})$. After a 1-hr incubation at $-20^{\circ} \mathrm{C}$, the RN A was precipitated by centrifugation at $14,000 \mathrm{rpm}$ at $4^{\circ} \mathrm{C}$ for $30 \mathrm{~min}$. Pellets were washed with $70 \% \mathrm{EtOH}$ and allowed to air-dry. The RN A was then resuspended into $10 \mu \mathrm{l}$ of DEPC $\mathrm{H}_{2} \mathrm{O}$. Annealing reactions were performed in $65 \mathrm{~mm}$ Tris- $\mathrm{HCl}(\mathrm{pH} 8.3), 100 \mathrm{~mm}$ $\mathrm{KCl}, 4 \mathrm{~mm} \mathrm{MgC} \mathrm{M}_{2}$ contained 200 fmoles of gel purified $5^{\prime 32} \mathrm{P}$ labeled primer 1 (AAGATGAGAGGACAGCTAGAGCATATGAG), incubated $1 \mathrm{~min}$ at $95^{\circ} \mathrm{C}$ and chilled on ice. Reactions were then adjusted to $0.5 \mathrm{~mm}$ dNTPs and $10 \mathrm{~mm}$ DTT. Primer extension was performed by the addition 20 units of Superscript II RN aseH ${ }^{-}$reverse transcriptase (GIBCO BRL) and incubated at $50^{\circ} \mathrm{C}$ for $10 \mathrm{~min}$. Products were isolated by phenol extraction and EtOH precipitation and resolved on $6 \%$ sequencing gels. Sequencing ladders were generated with $5^{\prime 32} \mathrm{P}$-labeled primer 1 for PCR cycle sequencing (Epicentre Technologies) of a plasmid containing a cloned copy of the E. crassus telomerase RNA gene. Cleavage sites nearest the $5^{\prime}$ end of the telomerase RN A were definitively mapped with a primer complementary to the telomerase RNA nucleotides $69-100$ for reverse transcription (data not shown).

\section{Acknowledgments}

We are grateful to Jeff Kapler and members of the Shippen laboratory for critical reading of the manuscript. This work was supported by N ational Institutes of Health grant GM 49157 to D.E.S.

The publication costs of this article were defrayed in part by payment of page charges. This article must therefore be hereby marked 'advertisement' in accordance with 18 USC section 1734 solely to indicate this fact.

\section{References}

Beattie, T.L., W. Zhou, M.O. Robinson, and L. Harrington. 1998. Reconstitution of human tel omerase activity in vitro. Curr. Biol. 8: 177-180.

Bednenko, J., M. M elek, E.C. Greene, and D.E. Shippen. 1997. Developmentally regulated initiation of DNA synthesis by telomerase: Evidence for factor-assisted de novo telomere formation. EMBO J. 16: 2507-2518.

Bhattacharyya, A. and E.H. Blackburn. 1994. Architecture of telomerase RN A. EMBO J. 13: 5721-5730.

Blasco, M.A., W. Funk, B. Villeponteau, and C.W. Greider. 1995. Functional characterization and developmental regulation of mouse telomerase RN A. Science 269: 1267-1270.

Collins, K. and L. Gandhi. 1998. The reverse transcriptase component of the Tetrahymena telomerase ribonucleoprotein complex. Proc. Natl. Acad. Sci. 95: 8485-8490.

Collins, K., R. Kobayashi, and C.W. Greider. 1995. Purification of Tetrahymena telomerase and cloning of genes encoding the two protein components of the enzyme. Cell 81: 677686.

Coyne, R.S., D.L. Chalker, and M .-C. Yao. 1996. Genome downsizing during ciliate development nuclear division of labor through chromosome restructuring. Annu. Rev. Genet. 30: 557-578.

Fan, Q. and M.-C. Y ao. 1996. N ew telomere formation coupled with site-specific chromosome breakage in Tetrahymena thermophila. Mol. Cell. Biol. 16: 1267-1274.

Fan, X.Q. and C.M. Price. 1997. Coordinate regulation of G- and C strand length during telomere synthesis. Mol. Biol. Cell. 8: 2145-2155.

Feng, J., W.D. Funk, S.-S. Wang, S.L. Weinrich, A.A. Avilion, C.-P. Chiu, R.R. Adams, E. Chang, R.S. Allsopp, J. Yu, S. Le, M.D. West, C.B. Harley, W.H. Andrews, C.W. Greider, and B. Villeponteau. 1995. The RNA component of human tel omerase. Science 269: 1236-1241. 
Gandhi, L. and K. Collins. 1998. Interaction of recombinant Tetrahymena telomerase proteins p80 and p95 with telomerase RNA and telomeric DNA substrates. Genes \& Dev. 12: 721-733.

Greene, E.C., J. Bednenko, and D.E. Shippen. 1998. Flexible positioning of the tel omerase-associated nuclease leads to preferential elimination of nontelomeric DNA. Mol. Cell. Biol. 18: 1544-1552.

Greider, C.W. 1995. Telomerase biochemistry and regulation. In Telomeres (ed. E.H. Blackburn and C.W. Greider), pp. 3568. Cold Spring Harbor Laboratory Press, Cold Spring Harbor, NY.

Greider, C.W. 1998. Telomerase activity, cell proliferation, and cancer. Proc. Natl. Acad. Sci. 95: 90-92.

Hammond, P.W. and T.R. Cech. 1997. dGTP-dependent processivity and possible template switching of Euplotes telomerase. Nucleic Acids Res. 25: 3698-3704.

Hammond, P.W., T.N. Lively, and T.R. Cech. 1997. The anchor site of telomerase from Euplotes aediculatus revealed by photo-cross-linking to single- and double-stranded DNA primers. Mol. Cell. Biol. 17: 296-308.

Harrington, L.A. and C.W. Greider. 1991. Telomerase primer specificity and chromosome healing. N ature 353: 451-454.

Harrington, L., W. Zhou, T. McPhail, R. Oulton, D.S. Yeung, V. Mar, M.B. Bass, and M.O. Robinson. 1997a. Human telomerase contains evolutionarily conserved catalytic and structural subunits. Genes \& Dev. 11: 3109-3115.

Harrington, L., T. McPhail, V. Mar, W. Zhou, R. Oulton, M.B. Bass, L. Arruda, and M.O. Robinson. 1997b. A mammalian telomerase-associated protein. Science 275: 973-977.

Klobutcher, L.A., M.T. Swanton, O. Donini, and D.M. Prescott. 1981. All gene-sized DNA molecules in four species of hypotrichs have the same terminal sequence and an unusual $3^{\prime}$ terminus. Proc. Natl. Acad. Sci. 78: 3015-3019.

Lee, M.S. and E.H. Blackburn. 1993. Sequence-specific DNA primer effects on telomerase polymerization activity. Mol. Cell. Biol. 13: 6586-6599.

Lingner, J. and T.R. Cech. 1996. Purification of tel omerase from Euplotes aediculatus: Requirement of a primer $3^{\prime}$ overhang. Proc. Natl. Acad. Sci. 93: 10712-10717.

Lingner, J., L.L. Hendrick, and T.R. Cech. 1994. Telomerase RN As of different ciliates have a common secondary structure and a permutated template. Genes \& Dev. 8: 1984-1998.

Lingner, J., T.R. Hughes, A. Shevchenko, M. Mann, V. Lundblad, and T.R. Cech. 1997. Reverse transcriptase motifs in the catalytic subunit of telomerase. Science 276: 561-567.

Lue, N.F. and Y. Peng. 1997. Identification and characterization of a tel omerase activity from Schizosaccharomyces pombe. Nucleic Acids Res. 25: 4331-4337.

Melek, M. and D.E. Shippen. 1996. Chromosome healing: Spontaneous and programmed de novo telomere formation by telomerase. BioEssays 18: 301-308.

Melek, M., E.C. Greene, and D.E. Shippen. 1996. Processing of nontel omeric $3^{\prime}$ ends by tel omerase: Default template alignment and endonucleolytic cleavage. Mol. Cell. Biol. 16: 3437-3445.

Meyerson, M., C.M. Counter, E.N. Eaton, L.W. Ellisen, P. Steiner, S.D. Caddle, L. Ziaugra, R.L. Beijersbergen, M.J. Davidoff, Q. Liu et al. 1997. hEST2, the putative human telomerase catalytic subunit gene, is upregulated in tumor cells during immortalization. Cell 90: 785-795.

Morin, G.B. 1989. The human telomere terminal transferase enzyme is a ribonucleoprotein that synthesizes TTAGGG repeats. Cell 59: 521-529.

N akamura, T.M. and T.R. Cech. 1998. Reversing time: Origin of telomerase. Cell 92: 587-590.

N akamura, T.M., G.B. Morin, K.B. Chapman, S.I. Weinrich, W.H. Andrews, J. Lingner, C.B. Harley, and T.R. Cech. 1997. Telomerase catalytic subunit homologs from fission yeast and human. Science 277: 955-959.

N akayama, J., M. Saito, H. N akamura, A. M atsuura, and F. Ishikawa. 1997. TPL1: A gene encoding a protein component of mammalian telomerase is a novel member of WD repeats family. Cell 88: 1-20.

Nugent, C.I. and V. Lundblad. 1998. The telomerase reverse transcriptase: Components and regulation. Genes \& Dev. 12: 1073-1085.

Prescott, D.M. 1994. The DNA of ciliated protozoa. Microbiol. Rev. 58: 233-267.

Prescott, J. and E.H. Blackburn. 1997. Functionally interacting tel omerase RN As in the yeast tel omerase complex. Genes \& Dev. 11: 2790-2800.

Romero, D.P. and E.H. Blackburn. 1991. A conserved secondary structure for telomerase RN A. Cell 67: 343-353.

Roth, M. and D.M. Prescott. 1985. DN A intermediates and telomere addition during genome reorganization in Euplotes crassus. Cell 41: 411-417.

Shippen, D.E. and T.D. M cKnight. 1998. Telomeres, telomerase and plant development. Trends Plant Sci. 3: 126-130.

Shippen-Lentz, D. and E.H. Blackburn. 1990. Functional evidence for an RN A template in tel omerase. Science 247: 546552.

Singer, M. and D.E. Gottschling. 1994. TCL1: Template RN A component of Saccharomyces cerevisiae telomerase. Science 266: 404-409.

Vermeesch, J.R. and C.M. Price. 1994. Telomeric DNA sequence and structure following de novo telomere synthesis in Euplotes crassus. Mol. Cell. Biol. 14: 554-566.

Wang, H. and E.H. Blackburn. 1997. De novo tel omere addition by Tetrahymena telomerase in vitro. EMBO J. 16: 866-879.

Wang, H., D. Gilley, and E.H. Blackburn. 1998. A novel specificity for the primer-template pairing requirement in Tetrahymena telomerase. EMBO J. 17: 1152-1160.

Weinrich, S.L., R. Pruzan, L. Ma, M. Ouellette, V.M. Tesmer, S.E. Holt, A.G. Bodnar, S. Lichtsteiner, N.W. Kim, J.B. Trager et al. 1997. Reconstitution of human telomerase with the template RNA component hTR and the catalytic protein subunit hTRT. Nat. Genet. 17: 498-502.

Yao, M.-C, C.-H. Yao, and B. Monks. 1990. The controlling sequence for site-specific chromosome breakage in Tetrahymena. Cell 63: 763-772.

Zaug, A.J. and T.R. Cech. 1995. Analysis of the structure of Tetrahymena nuclear RNAs in vivo: Telomerase RNA, the self-splicing rRN A intron, and U 2 snRN A. RNA 1: 363-364.

Zucker, M. 1989. On finding all suboptimal foldings of an RNA molecule. Science 244: 48-52. 


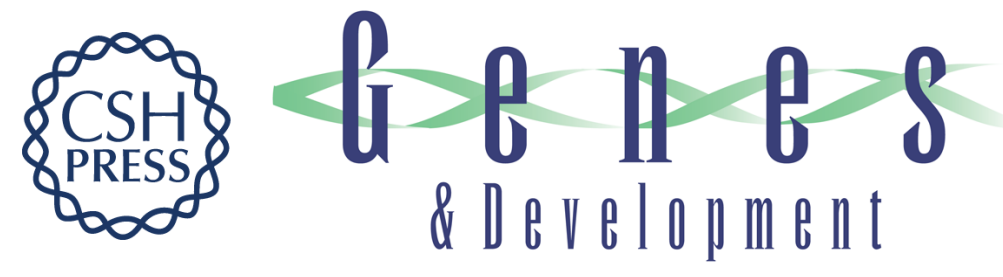

\section{Developmentally programmed assembly of higher order telomerase complexes with distinct biochemical and structural properties}

Eric C. Greene and Dorothy E. Shippen

Genes Dev. 1998, 12:

Access the most recent version at doi:10.1101/gad.12.18.2921

References

This article cites 46 articles, 29 of which can be accessed free at: http://genesdev.cshlp.org/content/12/18/2921.full.html\#ref-list-1

License

Email Alerting

Receive free email alerts when new articles cite this article - sign up in the box at the top Service right corner of the article or click here.

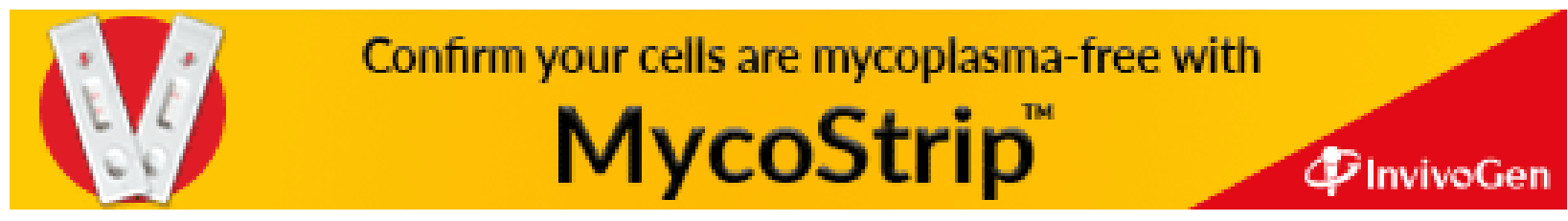

